\title{
Pulmonary hemorrhage syndrome associated with dengue fever, High-resolution computed tomography findings: a case report
} Edson Marchiori*1, José Luiz N Ferreira², Carolina N Bittencourt ${ }^{3}$, César A de Araújo Neto ${ }^{4}$, Gláucia Zanetti ${ }^{5}$, Cláudia M Mano ${ }^{6}$, Alair ASD Santos ${ }^{6}$ and Alberto D Vianna ${ }^{6}$

\begin{abstract}
Address: ${ }^{1}$ Fluminense Federal University, Rua Thomaz Cameron, 438, Valparaiso, CEP 25685.120, Petrópolis, Rio de Janeiro, Brazil, ${ }^{2}$ Hospital São Rafael, Salvador, Rua Dr Antonio Monteiro 105, Salvador, Bahia, Brazil, ${ }^{3}$ Hospital Otavio Mangabeira, Rua Pacifico Pereira, 457, Garcia, Salvador, Bahia, Brazil, ${ }^{3}$ Bahia Federal University, Rua Professor Clementino Fraga, 198, Ondina, Salvador, Bahia, Brazil, 5 Petrópolis Faculty of Medicine, Rua Coronel Veiga, 733, Centro, Petrópolis, Rio de Janeiro, Brazil and 'Fluminense Federal University, Rua Dr Paulo Alves, 110, Ingá, Niterói, Rio de Janeiro, Brazil

Email: Edson Marchiori* - edmarchiori@gmail.com; José Luiz N Ferreira - cdi-salvador@uol.com.br; Carolina N Bittencourt - cdisalvador@uol.com.br; César A de Araújo Neto - caaneto@gmail.com; Gláucia Zanetti - glauciazanetti@gmail.com;

Cláudia M Mano - cacaumano@gmail.com; Alair ASD Santos - alair@microlink.com.br; Alberto D Vianna - albertodvianna@terra.com.br

* Corresponding author
\end{abstract}

Published: 5 March 2009

Orphanet Journal of Rare Diseases 2009, 4:8 doi:10.1186/1750-1172-4-8

This article is available from: http://www.ojrd.com/content/4/I/8

(C) 2009 Marchiori et al; licensee BioMed Central Ltd.

This is an Open Access article distributed under the terms of the Creative Commons Attribution License (http://creativecommons.org/licenses/by/2.0), which permits unrestricted use, distribution, and reproduction in any medium, provided the original work is properly cited.
Received: 26 November 2008

Accepted: 5 March 2009

\begin{abstract}
Dengue hemorrhagic fever is an acute infectious disease caused by dengue virus. We described the high-resolution CT findings in a 70-year-old male with the disease, which was diagnosed by clinical examination and confirmed by serological methods. High-resolution CT demonstrated bilateral areas of consolidation with air bronchogram and ground glass opacities, as well as small bilateral pleural effusions. Dengue hemorrhagic fever should be considered in the differential diagnosis of diffuse pulmonary hemorrhage.
\end{abstract}

\section{Background}

Dengue fever (DF) is an acute infectious disease caused by dengue virus (DENV). It is a mosquito-borne flavivirus that belongs to the family Flaviviridae, and consists of four distinct serotypes (DENV 1-4) [1,2]. Dengue virus causes disease in humans, including dengue fever, dengue hemorrhagic fever (DHF) and dengue shock syndrome (DSS) $[1,2]$. The virus is transmitted to humans by the bite of infected female mosquitoes of the genus Aedes. Dengue disease has a wide spectrum of clinical signs and symptoms, ranging from asymptomatic infection to severe and lethal manifestations [3]. However, pulmonary hemorrhage and hemoptysis have been rarely described in the literature $[4,5]$.
The prevalence of dengue infection has grown dramatically in recent decades, and the disease is now endemic in more than 100 countries in Africa, the Americas, the Eastern Mediterranean, Southeast Asia and the Western Pacific $[6,7]$. The global resurgence of dengue is thought to be due to failure to control the Aedes populations, uncontrolled urbanization, population growth, climate change, and increasing number of international travelers [8].

In a review of the literature, we have found only one report describing the high resolution computed tomography (HRCT) findings in DHF [4]. The purpose of this study was to describe the high-resolution CT findings in a patient with dengue hemorrhagic fever, who presented with pulmonary hemorrhage and massive hemoptysis. 


\section{Case presentation}

A 70-year-old male presented to the Emergency Department with massive hemoptysis for the last 6 hours, respiratory distress, anemia, hemodynamic instability, and renal failure. He had a 6-day history of fever, intense headache, retro-orbital pain, arthralgia, myalgias, and dry cough. There were no gastrointestinal complaints. Supportive measures were taken and the patient was admitted to the intensive care unit (ICU) and placed on mechanical ventilatory support. On examination, he appeared anxious, pale and dyspneic, and inspection revealed ecchymoses over his arms and abdomen. His vital signs included a tachycardia of 110 beats/min (bpm), a respiratory rate of 32 breaths/min, a blood pressure of 90/50 $\mathrm{mmHg}$, and normal temperature $\left(36.8^{\circ} \mathrm{C}\right)$. Fine bibasilar crackles were present bilaterally. The remainder of the physical examination was unremarkable. Laboratory evaluation revealed a red blood cell (RBC) count of $2.53 \times$ $10^{6} / \mathrm{mm}^{3}$, hemoglobin level of $8.1 \mathrm{~g} / \mathrm{dL}$, hematocrit of $23.5 \%$ and platelet count of $50 \times 10^{3} / \mathrm{mm}^{3}$. His WBC count was $4.1 \times 10^{3} / \mathrm{mm}^{3}$, with a normal differential. Serum creatinine was $2.4 \mathrm{mg} / \mathrm{dL}$, urea, $90 \mathrm{mg} / \mathrm{dL}$, sodium, $135 \mathrm{mEq} / \mathrm{L}$, aspartate aminotransferase, $30 \mathrm{U} / \mathrm{L}$, alanine aminotransferase, $40 \mathrm{U} / \mathrm{L}$, alkaline phosphatase, $200 \mathrm{U} / \mathrm{L}$, gamma-glutamyl transpeptidase, $50 \mathrm{U} / \mathrm{L}$, albumin, $2.5 \mathrm{~g} /$ $\mathrm{dL}$, and globulin, $2.4 \mathrm{~g} / \mathrm{dL}$. Prothrombin time (PT) was $16.6 \mathrm{~s}(65 \%)$ and international normalized ratio (INR) was 1.4. Arterial gasometry showed metabolic acidosis. Chest radiograph demonstrated bilateral condensations, and HRCT revealed large areas of consolidation and ground glass attenuation in both lungs, predominantly in the right lung, and small bilateral pleural effusions (Figure 1 and Figure 2). The patient then underwent bronchofi-

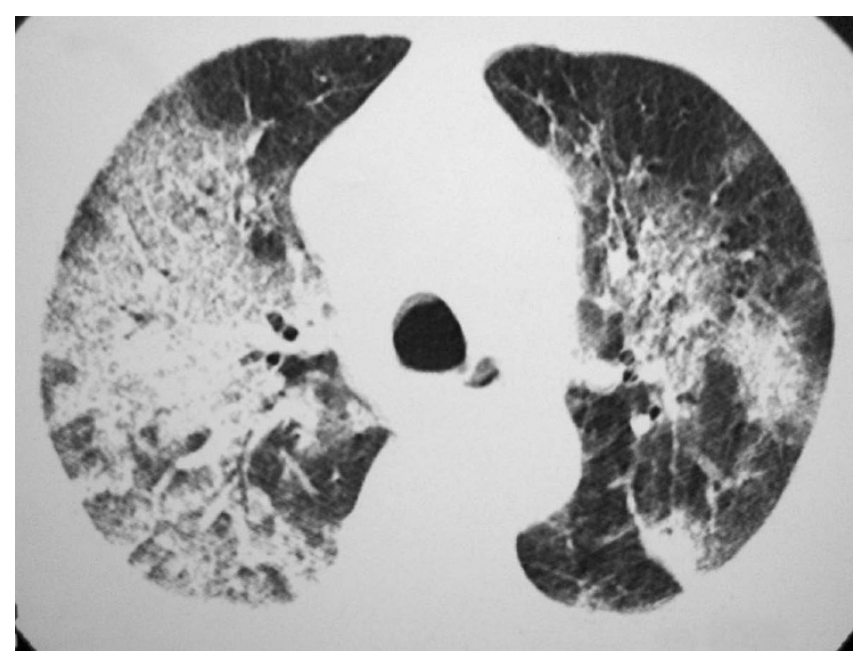

Figure I

HRCT showing extensive areas of consolidation with air bronchogram and ground glass opacities in both lungs, predominantly in the right lung.

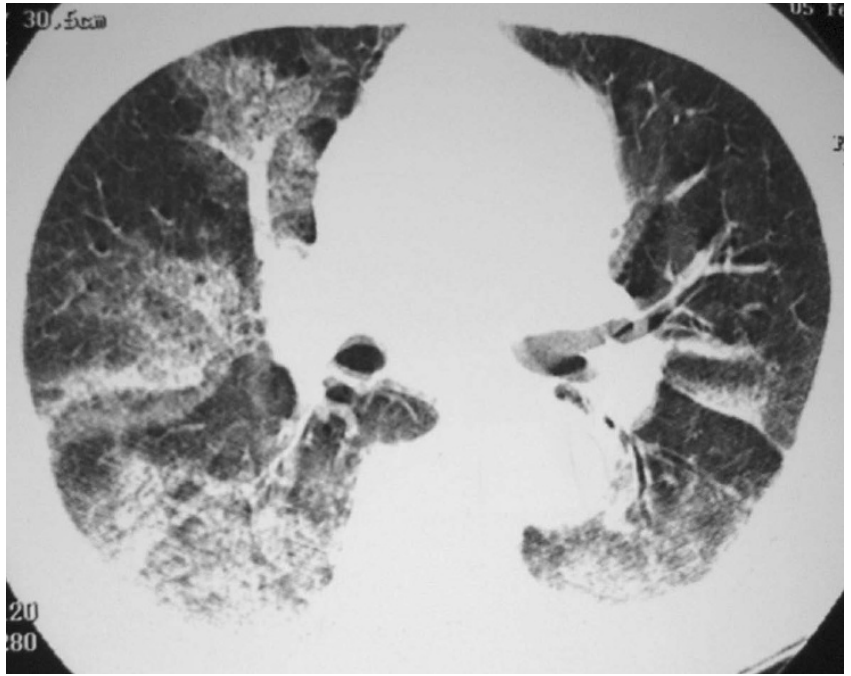

Figure 2

HRCT showing extensive areas of consolidation with air bronchogram and ground glass opacities in both lungs, predominantly in the right lung.

broscopy, which showed the presence of blood tinged secretion coming from both lungs, and friable mucosa with bleeding on touch. Lung biopsy was not performed because of coagulation abnormalities. Dengue serology, determined using a dengue IgM capture ELISA assay (MAC-ELISA), was positive. The patient required several blood transfusions, but developed refractory shock, severe metabolic acidosis, and died 15 days after admission.

\section{Discussion}

The clinical presentations of dengue include non-specific febrile illness, dengue fever, dengue hemorrhagic fever, and dengue shock syndrome. Dengue fever usually presents as an acute fever with headache, rash, myalgia, retro-orbital pain, arthralgia, prostration, lymphadenopathy, and leucopenia $[8,9]$. In general, laboratorial findings include neutropenia followed by lymphocytosis, presence of atypical lymphocytes and thrombocytopenia [9]. Virus can be detected in blood for 4 or 5 days after the onset of symptoms and then disappears as antibody (immunoglobulin $M[\operatorname{IgM}]$ ) production increases. In primary infections, IgG antibody appears within a few days, whereas in secondary infections, the IgG level rises immediately after the onset of symptoms and remains high in most patients [8].

Early diagnosis of DV infection is important and can be provisionally established by clinical observation and easily available laboratory tests. The presence of high fever of acute onset associated with a positive tourniquet test and hemoconcentration (increase of the hematocrit of $20 \%$ or more) or thrombocytopenia are sufficient to establish a 
provisional diagnosis of DHF, but a negative tourniquet test does not rule out dengue infection. Low platelet counts do not predict clinically significant bleeding in dengue, and DHF or dengue shock syndrome cases frequently have compensated consumptive coagulopathy that seldom requires treatment [7]. Therefore, platelet or blood transfusions are only indicated in cases where coagulopathy causes massive bleeding [10]. Currently, dengue diagnosis is based on serology, viral isolation and RNA detection. Enzyme-linked immunosorbent assays (ELISA) are still the most widely used technique for serological diagnosis, but they do not identify the dengue virus serotype responsible for the current infection [11].

According to WHO guidelines [10], our patient showed the criteria for defining a case of DHF, since he presented all of the following signs and symptoms: fever lasting 2-7 days; hemorrhagic tendencies, evidenced by the presence of ecchymoses and bleeding from the respiratory tract (hemoptysis); thrombocytopenia less than 100,000 cells per $\mathrm{mm}^{3}$; and evidences of plasma leakage, manifested by pleural effusion and hypoproteinaemia. Other manifestations of dengue fever were also present, including headache, myalgia, arthralgia, leucopenia and a positive IgM antibody test.

Dengue hemorrhagic fever is characterized by an increase in capillary permeability, which results in fluid extravasations (pleural effusion, ascites), and haemostatic changes, including decreased platelet levels near the time of defervescence and hemorrhagic manifestations [2,9]. Major hemorrhage is unusual except when in association with profound or prolonged shock [6]. The liver may be enlarged and serum activity of aminotransferases is usually increased [12]. DHF can also progress to DSS, which is associated with hypotension caused by severe plasma leakage $[2,12]$.

Thoracic manifestations such as pleural effusion and pneumonitis, are uncommon in DHF, and pulmonary hemorrhage is even more rare. Hemoptysis has been reported in $1.4 \%$ of dengue infections. The pathogenesis of bleeding in DHF patients is not well understood. It is thought to be a multifactorial process with abnormalities in the coagulation cascade, thrombocytopenia, platelet dysfunction, disseminated intravascular coagulation, and vascular defects. Vascular permeability has been thought to be mediated by histamine release $[4,5]$. Our patient presented with hemoptysis, and, for this reason, he underwent HRCT for the investigation of pulmonary hemorrhage. HRCT revealed extensive areas of consolidation with air bronchogram and ground glass opacities in both lungs, predominantly in the right lung, and small bilateral pleural effusions. By contrast, the only report of the HRCT findings found in the literature described the presence of discrete patchy ground glass opacities in both lungs, which regressed after conservative treatment.

Morphological studies of lung tissues revealed interstitial pneumonia associated with focal or diffuse zones of alveolar congestion and hemorrhage, increase of alveolar macrophages number, recruiting of platelets, mononuclear, and polymorphonuclear cells $[3,12]$.

There is no specific treatment for dengue fever. However, careful clinical management frequently saves the lives of DHF patients. With appropriate intensive supportive therapy, mortality may be reduced to less than 1 per cent [7].

\section{Conclusion}

In conclusion, dengue hemorrhagic fever should be considered in the differential diagnosis of a patient with fever, hemoptysis, and diffuse pulmonary infiltration. The highresolution CT findings of dengue hemorrhagic fever consist of bilateral areas of consolidation with air bronchogram and ground-glass opacities, and bilateral pleural effusions.

\section{Competing interests}

The authors declare that they have no competing interests.

\section{Authors' contributions}

EM conceived the study. GZ, CMM and ADV research the literature review and prepared the manuscript. CNB, JLNF and CAAN diagnosed the patient and drafted the initial manuscript. CNB and AASMDS wrote the presentation of the case, and contributed to the discussion section. EM and ADV edit and coordinated the manuscript. All authors read and approved the final manuscript.

\section{Consent}

Written informed consent was obtained from the patient for publication of this case report and accompanying images. A copy of the written consent is available for review by the Editor-in-Chief of this journal.

\section{References}

I. Barth OM, Barreto DF, Paes MV, Takiya CM, Pinhão AT, Schatzmayr HG: Morphological studies in a model for dengue-2 virus infection in mice. Mem Inst Oswaldo Cruz 2006, 101:905-15.

2. Balmaseda A, Hammond SN, Pérez L, Tellez Y, Saborío SI, Mercado JC, Cuadra R, Rocha J, Pérez MA, Silva S, Rocha C, Harris E: Serotype-specific differences in clinical manifestations of dengue. Am J Trop Med Hyg 2006, 74:449-56.

3. Barreto DF, Takiya CM, Schatzmayr HG, Nogueira RM, Farias-Filho Jda C, Barth OM: Histopathological and ultrastructural aspects of mice lungs experimentally infected with dengue virus serotype 2. Mem Inst Oswaldo Cruz 2007, 102:175-82.

4. Sharma SK, Gupta BS, Devpura G, Agarwal A, Anand S: Pulmonary haemorrhage syndrome associated with dengue haemorrhagic fever. J Assoc Physicians India 2007, 55:729-30.

5. Setlik RF, Ouellette D, Morgan J, McAllister CK, Dorsey D, Agan BK, Horvath L, Zimmerman MK, Purcell B: Pulmonary hemorrhage syndrome associated with an autochthonous case of dengue hemorrhagic fever. South Med J 2004, 97:688-91. 
6. Tagore S, Yim CF, Kwek K: Dengue haemorrhagic fever complicated by eclampsia in pregnancy. Singapore Med J 2007, 48:e28I-3.

7. Chaturvedi UC: The curse of dengue. Indian J Med Res 2006, I 24:467-70.

8. Tavakoli NP, Tobin EH, Wong SJ, Dupuis AP 2nd, Glasheen B, Kramer $L D$, Bernard KA: Identification of dengue virus in respiratory specimens from a patient who had recently traveled from a region where dengue virus infection is endemic. J Clin Microbiol 2007, 45: 1523-7.

9. Suzuki S, Kitazawa T, Ota Y, Okugawa S, Tsukada K, Nukui Y, Hatakeyama S, Yamaguchi D, Matsuse S, Ishii T, Matsubara T, Yamauchi C, Ota S, Yahagi N, Fukayama M, Koike K: Dengue hemorrhagic shock and disseminated candidiasis. Intern Med 2007, 46: 1043-6.

10. World Health Organization: Dengue haemorrhagic fever: diagnosis, treatment, prevention and control. 2nd edition. World Health Organization, Geneva; 1997.

11. De Paula SO, Fonseca BA: Dengue: a review of the laboratory tests a clinician must know to achieve a correct diagnosis. Braz J Infect Dis 2004, 8:390-8.

12. Basílio-de-Oliveira CA, Aguiar GR, Baldanza MS, Barth OM, Eyer-Silva WA, Paes MV: Pathologic study of a fatal case of dengue-3 virus infection in Rio de Janeiro, Brazil. Braz J Infect Dis 2005, 9:34I-7.

Publish with Bio Med Central and every scientist can read your work free of charge

"BioMed Central will be the most significant development for disseminating the results of biomedical research in our lifetime. "

Sir Paul Nurse, Cancer Research UK

Your research papers will be:

- available free of charge to the entire biomedical community

- peer reviewed and published immediately upon acceptance

- cited in PubMed and archived on PubMed Central

- yours - you keep the copyright 